over into the absorber and back 10-15 times; allow the mercury to fall until $\mathrm{KOH}$ level returns to zero (this is accomplished by using the cock $(\mathrm{C})$ to regulate rate of fall and the screw clip (S) for final fine adjustment) ; read the $\% \mathrm{CO}_{2}$ off the burette ; repeat passage to check that absorption is complete. The analysis takes less than two minutes from start to finish.

Accuracy.-Serial analyses are reproducible to within $\pm 0.05 \%$. Several comparisons both with the standard Haldane and with Lloyd's modification (Lloyd, 1958) gave agreement which was usually within $\pm 0.05 \%$ and never outside $0.1 \%$. This degree of accuracy is more than adequate for the purpose for which the instrument is intended.

\section{Modified Instrument}

The insert shows an alternative arrangement which, at the expense of the complexity of two taps instead of one, slightly speeds up the analyses and facilitates servicing. The calibrated volume includes the bores of the two taps and the connecting tube. The instrument is left with tap 1 (T) and tap $2(\mathrm{I})$; turn tap $2(\mathrm{~F})$ and adjust $\mathrm{KOH}$ level to zero. Tap 2 is then turned ( $\mathbf{L}$ ) ; the mercury is forced up into the stem of tap 1 and the sample of air is flushed through both taps; tap 1 is turned $(-1)$ and the sample is introduced to $0(10 \mathrm{ml}$ ) ; tap 1 is turned $(-)$; tap 2 is turned $(-\rightarrow)$; the zero level is checked, and absorption carried out as described above, Cleaning through with acid can be done with tap 2 ( I ) without needing to empty the $\mathrm{KOH}$ from the absorption pipette.

I am grateful to Dr. C. J. Dickinson and Dr. J. B. L. Howell for help in developing this analyser, and to $\mathrm{Mr}$. Richard Neave for preparing the illustration. The instruments have been made for me by Aimer Products, Rochester Place, Camden Town, London, N.W.1.

\section{REFERENCES}

Campbell, E. J. M., and Howell, J. B. L. (1960). Brit. med. J., 1, 458.

Haldane, J. S., and Graham, J. I. (1935). Methods of Air Analysis, 4th ed Griffin, London

Lloyd, B. B. (1958). J. Physiol. (Lond.), 143, 5P.

A Report on Electrical Accidents and their Causes, 1958 (H.M.S.O., price 5s. net), published on December 30, points out that, a!though it is just 50 years since the Electricity Regulations were made, they still provide an adequate legal basis for the prevention of accidents on premises covered by the Factories Acts, because it has always been possible to interpret them in terms of the current state of electrical engineering science and practice. "Looking back," the report continues, "to the report of the Chief Inspector of Factories for 1907, the year immediately before the Regulations were drafted, it is interesting to note that there were already 264 accidents during the year, of which eight were fatalities. In 1958 the number of accidents had only risen to 714 , including 38 fatalities. This is not unsatisfactory. when one considers the enormous increase in electrical supply, and industrial use since that time." Of the 714 accidents which were reported under the Factories Acts, 127 were welders' conjunctivitis or " eye-flash." "Unfortunately," the report records, "the decrease in the number of accidents in 1957 has not been maintained, and this is particularly noticeable when the figures for electrical accidents excluding eye flash are compared for the two years, there having been 527 accidents in 1957 and 587 accidents in 1958. Tables in the report analyse reported accidents by occupation and by causation." (Ministry of Labour Information Service, December, 1959.)

\section{SIMPLE RAPID METHODS OF ESTIMATING ARTERIAL AND MIXED VENOUS $\mathrm{PCO}_{2}$}

\author{
BY
}

\section{E. J. M. CAMPBELL, M.D., Ph.D., B.Sc., M.R.C.P.}

AND

J. B. L. HOWELL, Ph.D., M.B., B.Sc., M.R.C.P. Medical Unit, Middlesex Hospital, London

The aims of this paper are, first, to describe simple rapid methods for estimating mixed venous and arterial $\mathrm{pCO}_{2}$ and, secondly, to describe an evaluation of their accuracy in clinical disorders in which the carbon dioxide and hydrogen-ion concentration are disturbed.

\section{Physiological and Clinical Significance of Measurements of Blood $\mathrm{CO}_{2}$ Tension}

The arterial $\mathrm{CO}_{2}$ tension $\left(\mathrm{pCO}_{2}\right)$ defines the ratio between metabolism and the effective volume of the breathing-that is, alveolar ventilation.

$$
\text { Arterial } \mathrm{pCO}_{2} \propto \frac{\text { Vol. of } \mathrm{CO}_{2} \text { produced }}{\text { Alveolar ventilation }}
$$

The ratio between the volume of $\mathrm{CO}_{2}$ production and alveolar ventilation-and hence the $\mathrm{pCO}_{2}$-remains relatively constant in health over a wide range of $\mathrm{CO}_{2}$ production.

If alveolar ventilation is inadequate the $\mathrm{pCO}_{2}$ rises: if alveolar ventilation is excessive the $\mathrm{pCO}_{2}$ falls. The arterial $\mathrm{CO}_{2}$ tension is a much more reliable measure of effective ventilation than respiratory rate, depth or minute-volume, because these only indicate total ventilation, of which the effective (alveolar) portion is a very variable part.

Proof of inadequate ventilation (ventilatory failure) demands an estimation of arterial $\mathrm{pCO}_{2}$. Similarly, firm conclusions that treatment has improved ventilation can only be justified by estimations of arterial $\mathrm{pCO}_{2}$.

The arterial $\mathrm{pCO}_{2}$ also describes the respiratory component of disturbances in hydrogen-ion regulationthe relationship between $p \mathrm{H}$, bicarbonate concentration (which defines the metabolic component), and $\mathrm{pCO}_{2}$. being expressed in the Henderson-Hasselbalch equation.

$$
p \mathrm{H}=\mathrm{pK}^{\prime}+\log \frac{\text { bicarbonate concentration }(\mathrm{mEq} / \mathrm{l} \text {.) }}{0.03}
$$

Respiratory acidosis implies a raised $\mathrm{pCO}_{2}$ (above $44 \mathrm{~mm} . \mathrm{Hg}$ ). Respiratory alkalosis implies a reduced $\mathrm{pCO}_{2}$ (below $36 \mathrm{~mm}$. $\mathrm{Hg}$ ).

The arterial $\mathrm{pCO}_{2}$ is so informative and unequivocal that it would be measured in the diagnosis and assessment of a wide range of clinical problems were it not for the technical difficulty of its measurement. In this paper we describe a method by which the arterial $\mathrm{pCO}_{2}$ can be estimated at the bedside in a few minutes by a method requiring little technical skill ; and, if necessary, using very simple and inexpensive equipment.

\section{Methods Employed in Estimation of $\mathrm{pCO}_{2}$}

1. Arterial Blood, or arterialized blood (Brooks and Wynn, 1959). -The $\mathrm{pCO}_{2}$ can be measured (a) "directly" by Riley's method (Riley, Campbell, and Shepard, 1957); (b) "indirectly" by measuring the $p \mathrm{H}$ and blood $\mathrm{CO}_{2}$ content and calculating $\mathrm{pCO}_{2}$ from the Henderson- 
Hasselbalch equation; (c) with a special electrode (Severinghaus and Bradley, 1958). The analytical techniques are all expensive, difficult, or time-consuming.

2. "Alveolar" Air.-In normal subjects the $\mathrm{pCO}_{2}$ in expired alveolar air is equal to arterial $\mathrm{pCO}_{2}$. Expired alveolar air can be obtained by the Haldane-Priestley technique or by the use of an end-tidal sampler and analysed, using rapid and simple methods. Unfortunately, the Haldane-Priestley technique requires training and co-operation and the end-tidal sampling methods require special apparatus. Moreover, neither is reliable in patients who have disease of the lungs or who are receiving artificial ventilation, because in such circumstances expired alveolar air has a lower $\mathrm{pCO}_{2}$ than the arterial blood.

3. Mixed Venous Blood.-The $\mathrm{pCO}_{2}$ of mixed venous blood can be estimated by analysis of alveolar air after this has come into equilibrium with the mixed venous blood. We have reviewed the history and physiological problems of methods based on this principle (Campbell and Howell, 1960), which was originally introduced by Plesch (1909). We concluded that Collier's (1956) method was the most promising for routine clinical use.

\section{Collier's Method}

The subject rebreathes from a small (1 1.) bag containing $\mathrm{CO}_{2}$ (in air or $\mathrm{O}_{2}$ ) at a tension estimated to be somewhat higher than that of the mixed venous blood. After two or three breaths the gas in the bag mixes with the alveolar air (whose $\mathrm{pCO}_{2}$ is lower than mixed venous) to produce a $\mathrm{pCO}_{2}$ close to that of the mixed venous blood. The venous blood gives off or takes up $\mathrm{CO}_{2}$ from the mixture until complete equilibrium is reached; and then blood enters and leaves the lungs without changing its $\mathrm{pCO}_{2}$ and air goes to-and-fro from the bag to the lungs without changing $\mathrm{pCO}_{2}$. These events must be complete within a time limit set by the circulation, because blood which has left the lungs unable to give off $\mathrm{CO}_{2}$ passes to the tissues and returns with a higher $\mathrm{pCO}_{2}$ than previously. About 20 seconds elapse before this recirculation causes the alveolar and bag $\mathrm{pCO}_{2}$ to start rising.

Collier showed that the equilibrium could be detected as a "plateau" in the record of $\mathrm{pCO}_{2}$ measured at the mouth with a rapid analyser (Fig. $1 \mathrm{~A}$ ). If a plateau is not obtained the initial $\mathrm{pCO}_{2}$ in the bag is considered to be inappropriate and a higher or lower $\mathrm{pCO}_{2}$ is used, depending on the shape of the record. A trial-and-
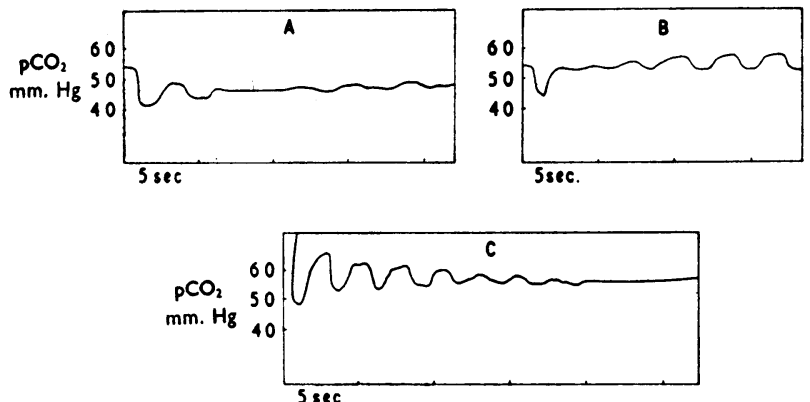

FIG. 1.-Records of $\mathrm{pCO}_{2}$ at the mouthpiece during rebreathing from a bag of 1.5-2 1. volume. A: Good plateau. B: Bad plateau. Note the early appearance, short duration, and large cyclical variation in subsequent breaths. C: Bad plateau. Note the very late appearance $A$ was obtained from a normal subject. $B$ was obtained from a patient with emphysema and mild ventilatory failure (arterial pCO $55 \mathrm{~mm}$. Hg). C was obtained from a normal subject who rebreathed deeply from a bag containing an C error procedure such as this is followed until a "good" plateau is obtained. With a suitable range of cylinders containing different $\mathrm{CO}_{2}$ concentrations, the mixed venous $\mathrm{pCO}_{2}$ can be determined in less than 10 minutes. Hackney, Sears, and Collier (1958) compared the mixed venous $\mathrm{pCO}_{2}$ estimated in this way with the arterial $\mathrm{pCO}_{2}$ in 60 patients, and found it to be, on the average, $6 \mathrm{~mm}$. $\mathrm{Hg}$ higher than the arterial. By subtracting this value from the mixed venous $\mathrm{pCO}_{2}$, the arterial $\mathrm{pCO}_{2}$ was estimated with a standard error of $\pm 2.9 \mathrm{~mm}$. $\mathbf{H g}$ and the maximum observed discrepancy was $\pm 5.3 \mathrm{~mm}$. $\mathrm{Hg}$.

We have found Collier's method to be excellent, but it necessitates the use of a rapid continuous $\mathrm{CO}_{2}$ analyser. We have tried to extend its use to circumstances in which such an instrument is not available.

The problems were: (1) to prepare for each subject a $\mathrm{CO}_{2}$ mixture with a $\mathrm{pCO}_{2}$ suitable for use as the starting gas for the rebreathing procedure; (2) to see if rebreathing such a mixture for a standard time would give results of an accuracy comparable to that obtained when a continuous record of $\mathrm{pCO}_{2}$ is available to indicate equilibrium; (3) to see if such a method would be reliable in patients with diseased chests and/or other disorders of $\mathrm{CO}_{2}$ regulation. We have previously described (Campbell and Howell, 1960) how a $\mathrm{CO}_{2}$ mixture 4-10 $\mathrm{mm}$. $\mathrm{Hg}$ greater than mixed venous blood can be produced in normal subjects by rebreathing 21 . of $100 \% \mathrm{O}_{2}$ for 90 seconds. In this paper we report an extension of this observation to patients with a wide range of disorders and compare the findings with direct determinations of arterial $\mathrm{pCO}_{2}$.

\section{Methods}

Arterial $\mathrm{pCO}_{2}$ was measured by Riley's method (Riley et al., 1957) and corrected for temperature (Bradley, Stupfel, and Severinghaus, 1956). Rebreathed gas mixtures were analysed continuously with an infra-red analyser (ird-o-meter) which sampled from the neck of the bag, and at specified times with either a Haldane apparatus or a simplification of it (Campbell, 1960).

Fifteen studies were carried out in the following manner.

Sequence 1.-(A) The subject rebreathed 21 . of $100 \%$ $\mathrm{O}_{2}$ for 90 seconds. The $\mathrm{pCO}_{2}$ in the bag was measured. (B) After not less than 2 minutes the subject rebreathed from the same bag for 20 seconds. The $\mathrm{pCO}_{2}$ in the bag was measured and the continuous record examined for a plateau. Arterial blood was withdrawn 5-10 minutes later.

Sequence 2.-(A) The subject rebreathed 1-1.5 1. of $100 \%$ $\mathrm{O}_{2}$ for 90 seconds. (This reduction in volume was made only if the tidal volume was small enough.) The $\mathrm{pCO}_{2}$ in the bag was measured. (B) The subject then rebreathed from this bag for 40 seconds. The $\mathrm{pCO}_{2}$ in the bag was measured and the continuous record examined for a plateau.

Sequence 3 (Carried out only if neither of the previous ones had produced an acceptable plateau). - The subject rebreathed a mixture of $\mathrm{CO}_{2}$ in $\mathrm{O}_{2}$ whose $\mathrm{pCO}_{2}$ was 7-14 $\mathrm{mm}$. $\mathrm{Hg}$ above that of the mixed venous blood as estimated in the previous sequences.

We sampled the arterial blood between the first two stages of the study to minimize scatter due to random variations of $\mathrm{pCO}_{2}$. We were aware that oxygen might cause hypoventilation, but repeated measurements of mixed venous $\mathrm{pCO}_{2}$ in these patients showed the effect to be negligible. Furthermore, if present, such an effect would make the first estimate of mixed venous $\mathrm{pCO}_{2}$ appear low in comparison with the arterial $\mathrm{pCO}_{2}$. The 
design of the study was thus biased against the rebreathing method.

The blood and gas measurements were made by separate observers, and no results were revealed until the study was completed.

Subjects.-The diagnosis of each of the patients is indicated in Table I. They were studied in the wards of the hospital by kind permission of the consultant staff. The patient with thyrotoxicosis had a B.M.R. $73 \%$ above normal. The patient in diabetic coma had, at the time of the first study, a $\mathrm{pH}$ of 7.12 and a plasma bicarbonate concentration of $6.3 \mathrm{mEq} / 1$. The patient with renal failure had a plasma bicarbonate concentration of $14 \mathrm{mEq} / \mathrm{l}$. and a haemoglobin concentration of $6 \mathrm{~g} . / 1$.

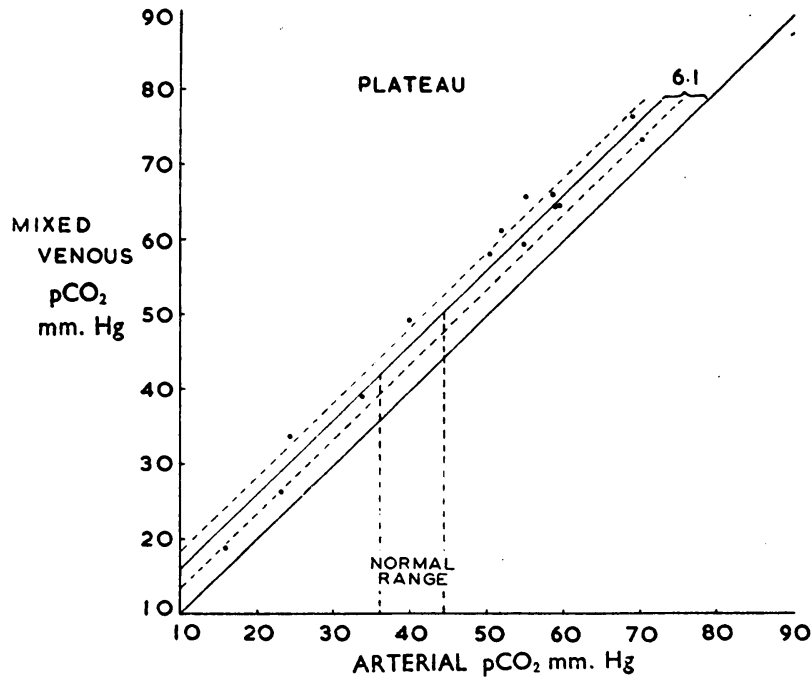

FIo. 2.-Comparison between the mixed venous $\mathrm{pCO}_{2}$ as estimated from the plateau obtained with the continuous analyser and the arterial $\mathrm{pCO}_{2}$.

\section{Results}

The results are presented in detail in Table $I$, and certain aspects of them are presented in Table II and Figs. 2 and 3.

Rebreathing 21 . of $\mathrm{O}_{2}$ for 90 seconds did not always create a $\mathrm{pCO}_{2}$ in the bag greater than that in the mixed venous blood either in the subjects with an arterial $\mathrm{pCO}_{2}$ which was abnormally high or in those in whom it was low. Furthermore, rebreathing the $\mathrm{CO}_{2}$ mixture so prepared did not yield a "good" plateau in most of the subjects. However, rebreathing this mixture for 20 seconds did produce a $\mathrm{pCO}_{2}$ in the bag about $6 \mathrm{~mm} . \mathrm{Hg}$ greater than the arterial $\mathrm{pCO}_{2}$ whether or not a plateau was obtained.

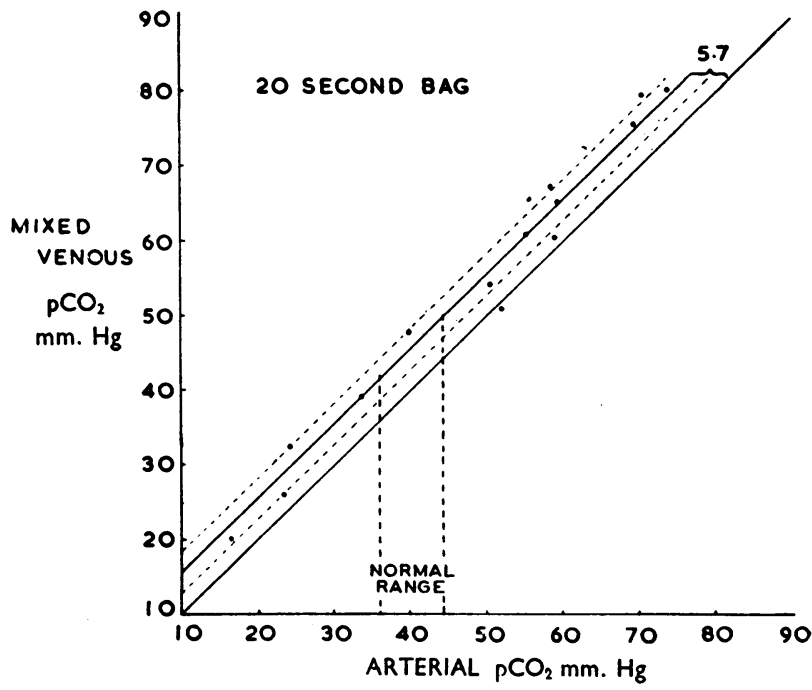

Fro. 3.-Comparison between the mixed venous $\mathrm{pCO}_{2}$ as estimated from the bag at the end of sequence 1 (" 20 -seconds bag") and the arterial $\mathrm{pCO}_{2}$.

TABLE I.-Results. The Order in Which these Measurements were Made is Explained in the Text

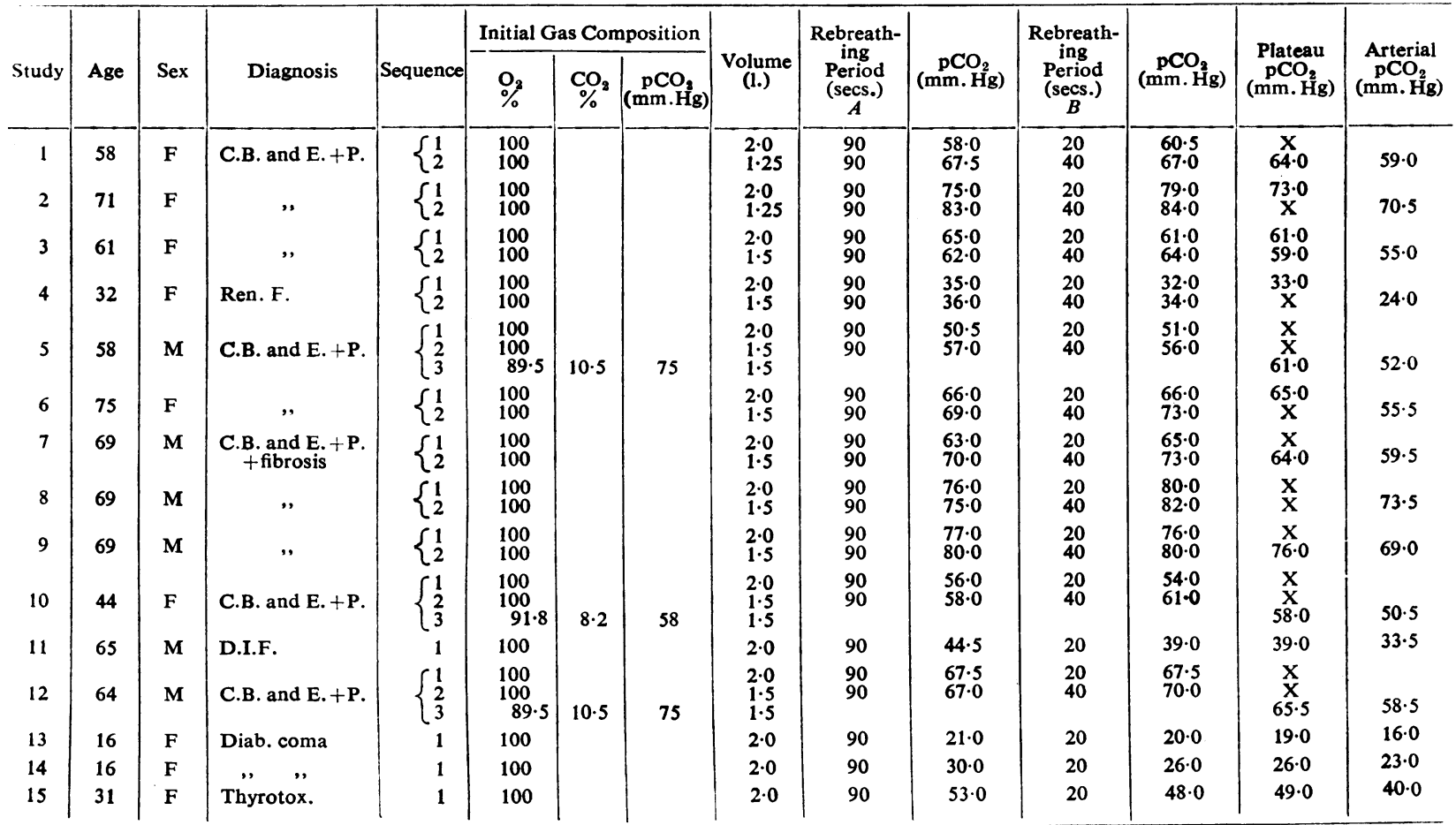

C.B. and E. + P. $=$ Chronic bronchitis and emphysema plus pneumonia. Ren.F. $=$ Renal failure. D.I.F. $=$ Diffuse interstitial fibrosis of the lungs. $\mathrm{X}=$ Plateau not obtained. 


\section{TABLE II}

\begin{tabular}{|c|c|c|c|}
\hline $\begin{array}{l}\text { Difference between (a) Arterial } \\
\mathrm{pCO}_{2} \text { (Riley) and }(b) \mathrm{pCO}_{2} \\
\text { Estimated by: }\end{array}$ & $\underset{(b-a)}{\text { Mean }}$ & S.D. & Range \\
\hline 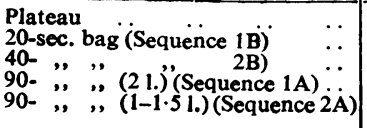 & $\begin{array}{r}6 \cdot 1 \\
5 \cdot 7 \\
10 \cdot 7 \\
5.9 \\
8.9\end{array}$ & $\begin{array}{l}2 \cdot 4 \\
2 \cdot 9 \\
3 \cdot 5 \\
5 \cdot 3 \\
3 \cdot 6\end{array}$ & 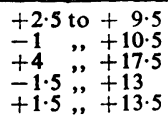 \\
\hline
\end{tabular}

When the initial volume of the bag was reduced to $1-1.51$. the $\mathrm{pCO}_{2}$ after 90 seconds usually exceeded mixed venous $\mathrm{pCO}_{2}$. "Good" plateaux were not, however, obtained more often during the subsequent rebreathing than were obtained in sequence 1 .

One or other of the three sequences yielded a good plateau in all but one of the studies. In the one exception a plateau seemed to have been obtained, but subsequent examination showed that the criteria laid down later (see Discussion) were not fulfilled. In the other studies the plateau $\mathrm{pCO}_{2}$ was on average 6.1 $\mathrm{mm}$. $\mathrm{Hg}$ greater than arterial (S.D. 2.4 ; range +2.5 to $+9.5)$.

The 40-seconds rebreathing period at the end of sequence 2 produced a $\mathrm{pCO}_{2}$ in the bag $10.7 \mathrm{~mm}$. $\mathrm{Hg}$ greater than arterial $\mathrm{pCO}_{2}$ (S.D. 3.5 ; range +4 to +17.5). This prolonged rebreathing period was included in the study because we believed that in patients with hypoventilation the equilibration with mixed venous blood might not occur in 20 seconds and this might lead to a serious underestimate of mixed venous $\mathrm{pCO}_{2}$. Our earlier studies of normal subjects had shown that the effect of recirculation (see above) was to cause only a small rise in the bag $\mathrm{pCO}_{2}(2-3 \mathrm{~mm}$. $\mathrm{Hg}$ between 20 and 40 seconds). If the 40 -seconds period at the end of sequence 2 produced a $\mathrm{pCO}_{2}$ in the bag which greatly exceeded that produced by the 20 -seconds period in sequence 1 , we anticipated that the 20 -seconds value would be found to underestimate the mixed venous $\mathrm{pCO}_{2}$ more than the 40 -seconds value overestimated it. In none of these patients was this found to be so. However, it may yet be found in patients with extremely high $\mathrm{pCO}_{2}$ values that the procedure according to sequence 2 is a valuable check on the standard procedure (that is, sequence 1).

\section{Discussion}

The failure of the initial rebreathing procedure in sequence 1 to produce a $\mathrm{pCO}_{2}$ above that of mixed venous blood is readily understandable in the subjects with a raised blood $\mathrm{pCO}_{2}$. More $\mathrm{CO}_{2}$ had to be added to the bag than in normal subjects, and the patients all had diseased lungs with an increased lung volume and poor distribution of the inspired air. The failure of the subjects with reduced $\mathrm{pCO}_{2}$ values to produce a high $\mathrm{pCO}_{2}$ in the bag by the initial procedure is less immediately understandable. Further work suggests that the finding may be due to the distribution of the $\mathrm{CO}_{2}$ formed in the actively metabolizing tissues in a larger effective "space" than is initially available in normal subjects. The blood-flow through many tissues in patients with anaemia or acidosis is probably greater than in normal subjects, and this will distribute the $\mathrm{CO}_{2}$ throughout the body more rapidly.

The arteriovenous $\mathrm{pCO}_{2}$ difference of about $6 \mathrm{~mm}$. $\mathrm{Hg}$, which we have found is the generally accepted value, the important consideration being that at rest it is small and relatively unaffected by changes in cardiac output (Suskind and Rahn, 1954).

Our results, in agreement with those of Hackney et al. (1958), show that the arterial $\mathrm{pCO}_{2}$ can be estimated by subtracting $6 \mathrm{~mm}$. $\mathrm{Hg}$ from mixed venous $\mathrm{pCO}_{2}$ as estimated by the rebreathing technique. In comparing our estimates of arterial $\mathrm{pCO}_{2}$ with the direct measurements four factors must be considered, all of which would tend to magnify the scatter of the results. (1) The arterio-mixed-venous $\mathrm{pCO}_{2}$ difference probably varies slightly. (2) The rebreathing method measures the $\mathrm{pCO}$ of "oxygenated" mixed venous blood rather than true mixed venous blood. The operation of the ChristiansenDouglas-Haldane effect causes the " oxygenated" mixed venous $\mathrm{pCO}_{2}$ to be about $2 \mathrm{~mm}$. $\mathrm{Hg}$ greater than the true value, this difference being greater when the cardiac output is low or when the alveolar and blood $\mathrm{O}_{2}$ tensions are low (Campbell and Howell, 1960). (3) The mixed venous and arterial $\mathrm{pCO}_{2}$ estimations could not be made simultaneously because the rebreathing procedure raises the arterial $\mathrm{pCO}_{2}$. This means that temporal variation in arterial $\mathrm{pCO}_{2}$ would add to the random error. The magnitude of this variation is not known but is probably greater in patients with ventilatory failure than in subjects with low or normal $\mathrm{pCO}_{2}$. (4) The direct determination of arterial blood $\mathrm{pCO}_{2}$ by Riley's method has a standard error of $\pm 1.7 \mathrm{~mm}$. $\mathrm{Hg}$ (Shepard and Meier, 1957). When these factors are considered, the agreement between the direct arterial $\mathrm{pCO}_{2}$ measurements and the estimations from the rebreathing method is good.

The results with the modified Collier technique, using the rapid $\mathrm{CO}_{2}$ analyser and also using the simplified procedure, are in good agreement with those obtained by Hackney et al. (1958). In routine clinical use our experience has confirmed the statement by Griggs et al. (1958): "the "rebreathing method' offers a simple reliable test for ventilatory failure which can be performed on the ward by a technician in less than 10 minutes. It can be performed on all types of patient, even on those who are comatose or confused." The demonstration that a rapid $\mathrm{CO}_{2}$ analyser, though allowing the equilibration process to be visualized and making the procedure somewhat quicker, is not essential has, we feel, brought the measurement of $\mathrm{pCO}_{2}$ into the realm of simple bedside techniques.

Practical Difficulties.-The only practical difficulty we have encountered is the prevention of leaks at the mouthpiece in unco-operative edentulous patients. We have been able to overcome this either by the use of an "everseal" anaesthetic mask or by the use of a mouthpiece with a large ( 4 by 2 in. ; 10 by $5 \mathrm{~cm}$.) flange. After putting this in the mouth it can be pulled outwards and the lips held down on to it.

Analytical Difficulties. - The simple chemical analyser we used presented no difficulties. Occasionally there was difficulty in deciding during Collier's procedure, using the rapid $\mathrm{CO}_{2}$ analyser, whether or not a plateau had been obtained. Hackney et al. (1958) define a satisfactory plateau as "an expired $\mathrm{CO}_{2}$ concentration that varied less than $0.1 \% \mathrm{CO}_{2}$ from the preceding inspired concentration achieved within 20 seconds after the start of rebreathing." We have quite often obtained records which fulfil this criterion but which would have given values too low (Fig. $1 \mathrm{~B}$ ). A phase-reversal of the $\mathrm{CO}_{2}$ concentration at the mouthpiece may occur as the air in the bag and in the lungs is mixed, and may mimic 
a plateau. Less commonly we have also seen apparent plateaux when too high an inspired $\mathrm{CO}_{2}$ concentration was used. This may occur in patients breathing very shallowly, when it is apparently due to inadequate exchange between the bag and the lungs; the gas in the neck of the bag and in the subject's dead space just passing to-and-fro by the sampling site. An extreme example, of course, is apnoea, which can be excluded by watching the movements of the bag. We have also observed an apparent plateau about $20-25$ seconds after the start of rebreathing in subjects who breathe deeply when very high inspired $\mathrm{CO}_{2}$ concentrations are used (Fig. $1 \mathrm{C}$ ). The probable explanation of this late plateau is that there is too much $\mathrm{CO}_{2}$ to be removed by the blood before recirculation. Equilibration therefore occurs with recirculated blood whose $\mathrm{pCO}_{2}$ was raised by the very high alveolar $\mathrm{pCO}_{2}$ present in the first 5-10 seconds.

As a result of these findings we suggest the following modification of Collier's definition of a satisfactory plateau: an inspired-expired $\mathrm{CO}_{2}$ concentration difference of less than $0.1 \%$ which is present in two successive breaths. Plateaux which occur within two breaths of the start of rebreathing or which take more than 15 seconds to appear should be regarded with suspicion.

\section{Conclusions}

The mixed venous and arterial $\mathrm{CO}_{2}$ tensions can be estimated accurately by rebreathing techniques.

The simplest method is to use a continuous $\mathrm{CO}_{2}$ analyser as described by Collier.

If such an instrument is not available it is still possible to estimate $\mathrm{pCO}_{2}$ with sufficient accuracy for clinical purposes in 5 to 10 minutes, using the following procedure: (1) Fill a bag with 1.5-2 1. of oxygen. (2) Rebreathe one and a half minutes. During first few breaths partially empty bag if tidal volume is less than half bag-volume. (3) Wait two minutes. (4) Rebreathe 20 seconds or five breaths (whichever is longer). (5) Analyse : bag $\mathrm{pCO}_{2}=$ mixed venous $\mathrm{pCO}_{2}$ (arterial approximately $6 \mathrm{~mm}$. $\mathrm{Hg}$ less). [Note: $(a)$ If in doubt, make 1 smaller; extend 2 as long as possible; extend 4 to 40 seconds. These should not increase bag $\mathrm{pCO}_{2}$ by more than $5 \mathrm{~mm}$. $\mathrm{Hg}$. (b) $\mathrm{pCO}_{2}$ of bag after initial one and a half minutes' rebreathing will give an approximate estimate of mixed venous $\mathrm{pCO}_{2}$ (Table II).]

\section{Summary}

The physiological significance of the measurement of arterial $\mathrm{pCO}_{2}$ is summarized and previous methods are reviewed.

Collier's rebreathing method for the estimation of the mixed venous and arterial $\mathrm{CO}_{2}$ tensions is outlined.

A simplification of Collier's method, eliminating the necessity for a continuous record of $\mathrm{CO}_{2}$ concentration, is described.

An evaluation of the method is described in patients with various disorders of $\mathrm{CO}_{2}$ and $p \mathrm{H}$ regulation showing that the accuracy is to within $\pm 3 \mathrm{~mm}$. $\mathrm{Hg}$.

Simple routines for the estimation of $\mathrm{pCO}_{2}$ are described for use both with and without continuous analysis of $\mathrm{CO}_{2}$.

We are grateful to Dr. A. Willcox, Professor A. Kekwick, Dr. G. D. Hadley, Dr. F. H. Scadding, and Dr. J. D. N. Nabarro for permission to study patients under their care ; and to Professor Kekwick for reading the manuscript.
The ird-o-meter was kindly lent to us by the Infra Red Development Co., Welwyn Garden City, Herts.

ADDENDUM.-Since this paper was prepared the method has been used for detecting the presence or absence of ventilatory failure in the following conditions: chronic bronchitis and emphysema, asthma, pneumonia, poliomyelitis, barbiturate poisoning, carbon-monoxide poisoning, head injury, cerebrovascular accidents, heart failure, myasthenia gravis, peripheral neuritis, post-anaesthetic collapse, post-thoracotomy distress, obesity, hypothyroidism, polycythaemia, and carcinoma of the bronchus. In several patients decisions about the use of artificial ventilation, tracheostomy, or other measures depended on the findings. It has also been used to evaluate the disordered hydrogen ion regulation of patients with diabetic coma, renal failure, pyloric stenosis, Addison's disease, Cushing's syndrome, potassium depletion, uretero-colic anastomosis, steatorrhoea, and tetany. Many of these measurements were made by junior medical staff or students.

\section{REFERENCES}

Bradley, A. F., Stupfel, M., and Severinghaus, J. W. (1956). J appl. Physiol.,9, 201.

Brooks, D., and Wynn, V. (1959). Lancet, 1, 227.

Campbell, E. J. M. (1960). Brit. med. J., 1, 457.

and Howell, J. B. L. (1960). pH and Blood Gas Measure ment: Methods and Interpretation, edited by $\mathrm{R}$. Woolmer. Churchill, London.

Collier, C. R. (1956). J. appl. Physiol., 9, 25.

Gollier, C. R. (1956). J. appl. Physiol., 9, 25. (1958). Amer. J. Med., 25, 31 .

Hackney, J. D., Sears, C. H., and Collier, C. R. (1958). J. appl Physiol., 12, 425 .

Plesch, J. (1909). Z. exp. Path. Ther., 6, 484-499.

Riley, R. L., Campbell, E. J. M., and Shepard, R. H. (1957). J. appl. Physiol., 11, 245.

Severinghaus, J W., and Bradley, A. F. (1958). Ibid., 13, 515

Shepard, R. H., and Meier, P. (1957). Ibid., 11, 250.

Suskind, M., and Rahn, H. (1954). Ibid., 7, 59.

\section{CHANGES IN FORCED EXPIRATORY VOLUMES THROUGHOUT THE DAY}

BY

\author{
H. C. LEWINSOHN, M.B., B.Ch.
}

Medical Registrar, London Chest Hospital

L. H. CAPEL, M.B., M.R.C.P.

Senior Medical Registrar, London Chest Hospital

AND

J. SMART, M.D., F.R.C.P.

Consultant Physician, London Chest Hospital

The early-morning exacerbation of their symptoms is often the bitterest complaint of patients suffering from chronic productive cough and breathlessness. The important immediate cause of this chronic breathlessness is probably persistent airway obstruction. An increase in the severity of this obstruction may cause the early-morning increase in breathlessness. This study was undertaken to show the magnitude of the change in the airways, and to find out whether it is peculiar to obstructive airway disease or whether it is part of a cycle of changes throughout the day present both in health and in airway disease.

\section{Methods and Results}

Five healthy men (mean age 30 years; mean forced expiratory volume $3,270 \mathrm{ml}$.) and 16 male patients with obstructive airway disease, 12 severely affected (mean 